\title{
OS CIRCUITOS DE TRABALHO INDÍGENA: POSSIBILIDADES E DESAFIOS PARA ACADÊMICOS E PROFISSIONAIS KAINGANG NA GESTÃO DAS POLÍTICAS PÚBLICAS
}

\author{
Wagner Roberto do Amaral ${ }^{1}$ \\ Michelle Aparecida Rodrigues ${ }^{2}$ \\ Jenifer Araujo Barroso Bilar ${ }^{3}$
}

\begin{abstract}
RESUMO
A atuação de profissionais indígenas formados pelas universidades públicas brasileiras é um fenômeno recente, sendo o Paraná, desde 2002, pioneiro na implementação de ações dessa natureza. Resultado de pesquisas realizadas, esse trabalho intenciona refletir sobre as trajetórias dos acadêmicos indígenas e a emergência de profissionais Kaingang na constituição de novos circuitos de trabalho, voltados à gestão de políticas sociais. Essas trajetórias evidenciam o duplo pertencimento desses sujeitos e a assunção das contradições envoltas nesse processo.
\end{abstract}

\footnotetext{
${ }^{1}$ Mestre e Doutor em Educação; Professor do Departamento de Serviço Social e do Programa de Pós-Graduação em Políticas Sociais e Serviço Social da Universidade Estadual de Londrina; Membro participante do Núcleo de Estudos e Pesquisas em Gestão de Políticas Sociais da UEL e da Comissão Universidade para os Índios do Paraná. E-mail para contato: wramaral2011@hotmail.com

${ }^{2}$ Assistente Social; Bolsista do Projeto de Extensão "Escola indígena e seu currículo: lugar de pertença e das identidades" desenvolvido pela UEL. E-mail para contato: mirodrigues129@gmail.com

${ }^{3}$ Estudante do curso de Serviço Social da Universidade Estadual de Londrina. Bolsista de Iniciação Científica. E-mail para contato: jhe_araujo@hotmail.com
} 
Palavras-chave: Educação superior indígena. Políticas afirmativas. Povos indígenas. Profissionais Kaingang.

\title{
CIRCUITS FOR INDIGENOUS WORK: POSSIBILITIES AND CHALLENGES FOR KAINGANG STUDENTS AND PROFESSIONALS IN THE MANAGEMENT OF PUBLIC POLICIES
}

\begin{abstract}
The work of indigenous professionals graduated by Brazilian public universities is a recent phenomenon being the State of Parana pioneering in the implementation of such actions since 2002. This work is a result of researches conducted to reflect on the trajectories of indigenous graduated students and the emergence of Kaingang professionals in the creation of new working circuits focused on the management of social policies. These trajectories reveal the dual belonging of these subjects and the assumption of contradictions shrouded in this process.
\end{abstract}

Keywords: Indigenous higher education. Affirmative policies. Indigenous peoples. Kaingang professionals.

\section{INTRODUÇÃO}

presença de estudantes indígenas nas universidades públicas brasileiras é
tão recente quanto o esboço de uma política pública afirmativa de educação
superior indígena no país. As trilhas percorridas pelos acadêmicos indígenas nas Universidades Estaduais do Paraná, desde 0 ano de 2002, tem se apresentado como um desafio no campo das políticas públicas de educação superior, considerando que a presença desses sujeitos no espaço acadêmico é nova e provocadora de significativas reflexões e possibilidades.

A experiência de gestão das políticas públicas de educação superior indígena, igualmente recente no Brasil, tem no estado do Paraná sua referência inédita e mais articulada do ponto de vista institucional, ainda que com imensas fragilidades (AMARAL, 2010). Entendemos que essa experiência tem em sua centralidade as trajetórias dos acadêmicos indígenas e a organização das Instituições de Ensino Superior Públicas no Paraná, devendo esses percursos serem compreendidos e analisados como referências importantes para problematizar, propor e avaliar as ações realizadas e as que ainda não foram implementadas. Esse percurso tem sido empreendido, em especial, por 
acadêmicos Kaingang que passam a compor novas relações sociais, políticas e culturais junto às suas comunidades de pertencimento.

Importa compreender que os esforços empreendidos por esses acadêmicos, apoiados por suas famílias e pelas suas comunidades, numa teimosia educativa em pertencer simultaneamente a espaços tão díspares - as aldeias e a Universidade - tem resultado na constituição de um circuito de trabalho Kaingang focado por eles na ocupação de espaços institucionais em órgãos públicos gestores de políticas sociais. Vislumbra-se, portanto, a emergência da constituição de um novo sujeito indígena e, portanto, Kaingang, com status profissional e intelectual, formado pelas universidades públicas e que passa a ser desafiado a manter seu duplo pertencimento na tarefa de gerir políticas pública.

\section{INGRESSO E PERMANÊNCIA DOS ACADÊMICOS INDÍGENAS NA EDUCAÇÃO SUPERIOR NO PARANÁ E SEU DUPLO PERTENCIMENTO}

0 ingresso, permanência e conclusão dos estudos pelos indígenas na educação superior é um fenômeno recente, datado dos últimos doze anos no Brasil. Poucos estudos foram realizados no país em torno desse fenômeno, mas as referências existentes buscam compreender como tem sido os percursos trilhados pelos acadêmicos indígenas a partir do seu ingresso e, principalmente, para permanecerem nas Universidades. Menos ainda têm se estudado sobre os percursos, as expectativas e as necessidades dos profissionais indígenas egressos da educação superior e as experiências que esses sujeitos vêm realizando nas instituições onde atuam.

Constata-se que o crescente ingresso de indígenas na educação superior é decorrente da progressiva ampliação da escolarização de crianças, jovens e adultos em terras indígenas. Apresenta-se contextualizado mediante o reconhecimento da Educação Escolar Indígena na Lei de Diretrizes e Bases da Educação Nacional (LDBEN), de 1996, no Plano Nacional de Educação, de 2001, nas Diretrizes Nacionais da Educação Escolar Indígena no Brasil, bem como na legislação recente que define a educação superior indígena, reconhecida oficialmente por meio da Lei Federal n. 12.416, de 09/06/2011, e que altera a LDBEN de 1996.

Contudo, também é na universidade pública que a presença indígena provoca ainda mais a evidenciação das contradições, dos paradoxos e das (in)coerências que nela residem e a constituem, fundamentalmente a partir das estratégias de ingresso e de permanência desses sujeitos no ambiente 
universitário. É nele que passam a se constituir e identificar como estudantes indígenas universitários - categoria emblemática uma vez que se forja a partir de relações sociais marcadas por interações, intercâmbios, contradições, resistências, resiliências, ocultamentos, negações e afirmações. É também no espaço acadêmico, mediado pelas relações de pertencimento étnico-comunitário, que passam a construir suas perspectivas de futuro profissional, voltando-se novamente para suas comunidades de origem e problematizando quais espaços ocupacionais passam a se constituir ou que podem ser constituídos para ingressarem numa nova condição: a de profissionais indígenas, nas mais variadas áreas.

No Paraná, a política de educação superior indígena é orientada pela Lei Estadual n. 13.134/2001, alterada pela Lei Estadual n.14.995/2006, que prevê aos indígenas, habitantes no território paranaense, o direito a vagas suplementares e uma política de ingresso específico nas Instituições de Ensino Superior. A lei foi sancionada em 18 de abril de 2001, prevendo inicialmente três vagas para cada uma das Universidades Estaduais do Paraná, fato inédito no país. Em 2006, a lei foi alterada garantindo seis vagas suplementares para cada Universidade paranaense. Para garantir o ingresso de candidatos indígenas, desde 2002 são organizados processos seletivos específicos por meio de Vestibulares Interinstitucionais dos Povos Indígenas do Paraná. No período de 2002 a 2014, foram realizados treze Vestibulares dos Povos Indígenas de forma itinerante nas IES públicas do Paraná, possibilitando o ingresso e permanência de indígenas nas IES estaduais e também na Universidade Federal do Paraná, garantindo contornos mais específicos para a política pública de educação superior indígena.

Emerge, desta forma, o primeiro desenho institucional de política pública de educação superior indígena no país, seguido de outros formatos em diferentes universidades. A legislação garantiu também aos acadêmicos indígenas o direito a uma bolsa auxílio, cujo valor foi progressivamente elevado ao longo da década .

No período de 2002 a 2008, as IES estaduais paranaenses disponibilizaram 189 vagas para indígenas, sendo aprovados 173 candidatos indígenas e, destes, matriculados 139 estudantes, permanecendo matriculados no ano de 2008

\footnotetext{
${ }^{4}$ Os estudantes indígenas vinculados às Universidades Estaduais recebem mensalmente uma bolsa auxílio no valor de $\mathbf{R} \$ 633,00$, acrescido em $50 \%$ quando comprovada a guarda de filho. Essa bolsa é repassada pelo Governo do Estado do Paraná, com variações nos seus valores desde o ano de 2002. Ainda não existem estudos mais específicos que analisem a relação possível entre 0 recebimento dessa bolsa com o prolongado tempo de permanência dos estudantes indígenas na graduação.
} 
apenas 76 deles. Cerca de $56,6 \%$ das vagas foram ocupadas por membros das comunidades Kaingang, em virtude de que esse grupo étnico se apresenta demograficamente com maior número de habitantes indígenas no território paranaense, seguido da população Guarani.

No ano de 2008, estavam concluindo os estudos e já formados quatorze estudantes indígenas, representando 29,4\% dos ingressantes no período de 2002 a 2004 , sendo oito Kaingang (53,3\% do total). No ano de 2013 o número de indígenas formados saltou para $39^{5}$. Um dado emblemático refere-se ao alto índice de evasão sendo que, dos 139 matriculados, cerca de 61 evadiram (43,9\%) por motivos diversos (AMARAL, 2010). Esses dados revelam as tentativas ainda frustradas de abertura do espaço acadêmico aos povos indígenas, uma vez que garantir 0 acesso sem consolidar a permanência não efetiva esse processo de democratização. Lembramos ainda que o espaço acadêmico revela características europeizadas, monoculturais, homogêneas, colonialistas e preconceituosas, mas que também pode passar a ser espaço de protagonismo e reconhecimento das potencialidades dos estudantes indígenas.

Para tanto, a política pública de educação superior indígena se evidencia como uma necessidade produzida por estes povos e suas organizações políticas, no contexto da sociedade capitalista e globalizada que, com 0 avanço das fronteiras urbanas e agro-industriais no país, passa a ofender e invadir os territórios habitados historicamente por diferentes grupos étnicos indígenas, dizimando parte dessas populações e influenciando suas identidades culturais e seus modos de vida (OLIVEIRA; FREIRE, 2006). Na conjuntura atual, essa ofensiva do modo de produção capitalista tem perpassado para além das fronteiras do território indigena de forma mais sutil, abstrata e fragmentada, isto é, as novas gerações desses povos vão cada vez mais adquirindo as referências e os valores desse mundo moderno (LUCIANO, 2006). As fronteiras étnicas (BARTH, 1998) e sociais passam a ser manifestas nos rituais de troca e intercâmbio entre indígenas e não indígenas, por vezes de formas violentas e por vezes por eles consensuadas.

Desde o período colonial, as ações de imposição econômica, política e ideocultural passam a criar e a recriar novas formas de subsistência nos territórios indígenas que, ao imporem um modelo de escola, provocam processos de descaracterização da vida na aldeia. Como resposta, os movimentos indígenas têm crescido e se apropriado do espaço escolar e acadêmico, hoje garantido

\footnotetext{
${ }^{5}$ Dado coletado pelo projeto de pesquisa "A trajetória formativa dos estudantes Kaingang e Guarani na UEL e na UEM, e a constituição de circuitos de trabalho indígena", desenvolvido pelo autor desse artigo, na Universidade Estadual de Londrina.
} 
legalmente. Essa apropriação pelos próprios indígenas cria novos processos de ressignificação da escola nos territórios indígenas, a partir das necessidades vivenciadas dentro desses territórios, numa perspectiva de afirmação de seu pertencimento étnico-cultural (PERES, 2007).

Um outro espaço que passa a ser recentemente apropriado pelos povos indígenas é o do ensino superior público. A partir do ingresso na universidade, os estudantes indígenas passam a viver seu processo formativo em trânsito entre suas aldeias de origem e a cidade. Considerando que as terras indígenas se localizam geograficamente distantes das cidades, muitas vezes em locais de difícil acesso, se observa uma ocupação dos estudantes indígenas não só o espaço acadêmico, mas também da cidade, passando a residir no espaço urbano ou mesmo, se deslocando com frequência a ele. Para tentarmos analisar os percursos trilhados cotidianamente por esses estudantes, buscamos compreendê-los como sujeitos de um duplo pertencimento: 0 pertencimento acadêmico e 0 pertencimento étnico-comunitário. Amaral (2010) considera 0 duplo pertencimento primordial para a permanência dos estudantes indígenas na universidade, visto que encontram a possibilidade de articularem-se ora indígenas, ora estudantes universitários, ocupando um território por eles novo e não conhecido.

0 duplo pertencimento carrega conceitualmente a lógica das possibilidades de permanência do e pelo estudante indígena na universidade, diante da permanente tensão e diálogo entre universos e sujeitos distintos e ao mesmo tempo relacionais. Estes passam a definir um novo campo de fronteira entre os diferentes grupos étnicos presentes (e alguns, sobreviventes) na universidade e entre esses e os diferentes sujeitos não indígenas que participam e constituem 0 ambiente universitário (AMARAL, 2010, p. 278).

Nessa perspectiva, os acadêmicos indígenas encontram-se diante de uma fronteira social e cultural entre a aldeia e a cidade, pela qual precisam estar em constante exercício de trânsito e circulação, pois é fundamental que se reconheçam indígenas, que mantenham os vínculos estabelecidos com suas comunidades de origem, mas que também ocupem a universidade e estabeleçam relações que venham a facilitar sua permanência neste novo espaço.

Ainda que ingressantes na Universidade e em processo de identificação, ocupação e estabelecimento de relacionamentos neste novo espaço social, os 
estudantes indígenas não podem perder de vista seu pertencimento étnicocomunitário, ou seja, sua identidade enquanto indígena. Se sentir indígena Kaingang, Guarani ou de outro grupo étnico - e pertencente a uma comunidade é fundamental para esses sujeitos que passam a carregar consigo as possibilidades, expectativas, necessidades e relações de poder faccionais - dependendo do grupo familiar que estejam vinculados -, existentes em suas comunidades de origem. Esse pertencimento inicia-se com a inscrição anual dos candidatos indígenas ao Vestibular dos Povos Indígenas do Paraná que, dentre os documentos a serem apresentados, precisam apresentar uma declaração do cacique da terra indígena em que pertencem para homologação nesse processo.

Uma das perspectivas para compreender o lugar e o sentido atribuído à Universidade pelos estudantes indígenas refere-se à possibilidade desses sujeitos assumirem postos de trabalho tradicionalmente desenvolvidos por profissionais não indígenas, principalmente em órgão públicos gestores e executores de políticas sociais nas aldeias e no seu entorno. Assim, emerge a preocupação em formar médicos, dentistas, enfermeiros, assistentes sociais, advogados, pedagogos, professores, dentre outros profissionais para atuarem em espaços ocupacionais existentes nas terras indígenas e/ou no seu entorno. Com isso, os indígenas podem reconhecer e conquistar o espaço acadêmico e os novos espaços e postos de trabalho que para eles se abrem, ocupando-os, partindo de uma perspectiva étnica, sendo protagonistas da história e não mais tutelados.

\section{OS PERCURSOS PARA A CONSTITUiÇÃo DE CIRCUitos DE TRABALHO KAINGANG}

Os Kaingang constituem um povo indígena que secularmente habita a Região Sul do Brasil e algumas regiões do Estado de São Paulo, tendo tido também, no passado, importante presença no território Argentino, em Missiones. Segundo o Censo IBGE 2010, as estimativas para sua população atual no Brasil representam em torno de 37.470 pessoas, das quais 31.814 vivem em 32 terras indígenas demarcadas e em outras que encontram-se em processo de ocupação fundiária por este povo para retomada de seus territórios tradicionais. Cerca de 5.656 pessoas desse grupo étnico vivem fora das terras indígenas (IBGE, 2010).

\footnotetext{
${ }^{6} 0$ ingresso de indígenas nas Universidades Públicas do Paraná vem se realizando desde 0 ano de 2002 por meio de concursos vestibulares interinstitucionais e específicos para os povos indígenas, coordenado pela Comissão Universidade para os Índios (CUIA), vinculada à Secretaria de Estado de Ciência, Tecnologia e Ensino Superior do Paraná.
} 
No Paraná, essa população habita 12 terras indígenas demarcadas e três terras indígenas em processo de ocupação fundiária e de tramitação do seu reconhecimento e demarcação.

Os registros históricos caracterizam os Kaingang como povo guerreiro (denominados pelos brancos, de forma estereotipada, como "selvagens"), pela incansável luta pelo seu território devido à intensificação do processo de invasão de suas terras (MOTA, 2000). o povo Kaingang, ao longo de sua história, se caracterizou por sua língua, pertencente ao grupo Jê meridional, fazendo dela um instrumento oral de identidade e também de resistência.

A relação dos Kaingang com a escrita do seu idioma data das últimas quatro décadas, considerando que sua língua foi altamente depreciada e desconsiderada no processo de escolarização desenvolvido pelas escolas instituídas pelo Serviço de Proteção ao Índio. Ressalta-se que essas escolas foram criadas para integração dos indígenas ao processo de desenvolvimento e modernização do país, com a explícita intenção do SPI em transformar os indígenas em trabalhadores nacionais, na perspectiva de suprimir, progressivamente, suas marcas identitárias, provocando a depreciação e a extinção das línguas indígenas existentes no Brasil (VEIGA; D'ANGELIS, 2000).

0 espaço escolar, nos padrões não indígenas dentro das terras indígenas ou fora delas, passa a compor e a impor uma estratégia de integração nacional, de controle e disciplinarização dos Kaingang. Cabe destacar que, contraditoriamente provocados por este movimento, ao longo desta história recente, os professores Kaingang, como sujeitos da escola indígena, passam a se apropriar, recompor e ressignificar o espaço escolar.

Ressalta-se ainda a progressiva apropriação e participação das lideranças Kaingang na gestão da política pública de educação escolar em nível estadual e nacional, sendo esse grupo étnico estratégico, uma vez em que se encontra entre os cinco maiores contingentes populacionais indígenas do país (TOMMASINO; FERNANDES, 2001).

Perpassa nesta relação, fundamentalmente, o espaço de relações sociais que compreende a escola para esse grupo étnico, influenciando e dinamizando 0 seu modo de organizar-se social, política e economicamente em seus territórios ${ }^{7}$, a

\footnotetext{
${ }^{7}$ Sobre as dimensões de pertença, interação e resistência cultural dos povos indígenas com o seu território, destacam-se os estudos de Kimyie Tommasino junto aos povos Kaingang, especificamente da Terra Indígena do Apucaraninha, região de Londrina/Paraná, principalmente no que se refere à relação de memória que este povo possui com sua ancestralidade, estando esta
} 
partir de sua própria cosmologia baseada no dualismo Jê (TOMMASINO, 1995; VEIGA, 1994, 2000). Evidencia-se também para o povo Kaingang o desafio em conhecer as potencialidades existentes no ensino superior, reconhecendo a estrutura e o funcionamento das universidades e identificando os benefícios dos quais podem se apropriar como direito.

Com 0 ingresso de estudantes Kaingang nas universidades estaduais paranaenses, por meio das edições do Vestibular dos Povos Indígenas do Paraná, se evidenciam as opções profissionais realizadas por esses sujeitos e suas famílias. Emerge, desta forma, a constituição de um novo circuito de trabalho Kaingang, que se faz desde os percursos dos estudantes Kaingang em seu processo de formação acadêmica nas universidades (mantendo-se nos cursos escolhidos ou pelas transferências de cursos e IES), até a conclusão do curso e atuação na sua comunidade de pertencimento ou em outras terras indígenas, dependendo do acolhimento a esse novo profissional ou da existência de vagas na sua área de formação. Portanto, a centralidade desse circuito está na emergência dos profissionais Kaingang recém-formados pelas universidades, bem como no acolhimento político-comunitário interno e na vinculação desses sujeitos para ocupar espaços e postos de trabalho nas suas comunidades.

Até 0 ano de 2014, foram ofertadas 450 vagas distribuídas para todas as IES estaduais do Paraná, ocupadas por acadêmicos Kaingang e Guarani em diversos cursos de graduação. Segundo Amaral (2010), as áreas profissionais mais procuradas pelos acadêmicos Kaingang são a Educação (representando 46,6\% do total) e a Saúde (representando 26,6\%), ao considerar os cursos por eles matriculados entre os anos de 2002 a 2008. Observa-se que as demais áreas profissionais também tem sido procuradas e são fundamentais para 0 desenvolvimento das terras indígenas, vindo a provocar a possível criação de postos de trabalho nas organizações públicas ou privadas, nas aldeias e fora delas, que venham a absorver essa nova força de trabalho.

Considerando o universo de indígenas que ingressaram nas Universidades Estaduais do Paraná, 37 concluíram seus cursos de graduação no período de 2006 à 2013. Destes, 17 são pertencentes à etnia Guarani e 20 são pertencentes à etnia Kaingang.

presente nas trilhas, nos rios e todo o espaço geográfico que constitui a terra indígena. A manutenção do território representa a manutenção da cultura e, consequentemente, a relação deste povo com sua ancestralidade (TOMMASINO, 2000). 


\section{Quadro 1 - profissionais Kaingang formados pelas Universidades Estaduais paranaenses no período de 2006 à 2013.}

\begin{tabular}{|c|c|c|}
\hline Descrição & $\begin{array}{c}\text { Número de } \\
\text { egressos }\end{array}$ & $\%$ \\
\hline Profissionais Kaingang formados & 20 & $100 \%$ \\
\hline $\begin{array}{c}\text { Profissionais Kaingang formados na área da Educação, sendo 09 em } \\
\text { Pedagogia e 02 em outras Licenciaturas }\end{array}$ & 11 & $55 \%$ \\
\hline $\begin{array}{c}\text { Profissionais Kaingang formados na área de Estudos Sociais Aplicados, } \\
\text { sendo: 03 Assistentes Sociais, 02 Advogados e 01 Administrador }\end{array}$ & 06 & $30 \%$ \\
\hline $\begin{array}{c}\text { Profissionais Kaingang formadas na área da Saúde, sendo todas } \\
\text { Enfermeiras }\end{array}$ & 03 & $15 \%$ \\
\hline
\end{tabular}

Fonte: Autores.

Cabe destacar que, dos 20 profissionais Kaingang formados, 17 são do sexo feminino e apenas três do sexo masculino, o que pode estar associado ao significativo número de formados na área da Educação (Pedagogia) e da Saúde (Enfermagem), comumente mulheres. Ainda que não haja reflexões acerca desses dados, entende-se fundamental o desenvolvimento de investigações que possam identificar as relações existentes entre a questão de gênero, a escolha dos cursos e os processos de permanência e terminalidade da graduação por acadêmicos Kaingang.

Ao analisar as trajetórias e experiências dos profissionais Kaingang egressos das Universidades Estaduais do Paraná (AMARAL, 2010), constatam-se três elementos estruturantes na constituição de um novo circuito de trabalho Kaingang nas terras indígenas. 0 primeiro se refere à significativa demanda para atuação de profissionais indígenas nas políticas públicas de educação e de saúde nas terras indígenas, em decorrência do avanço das legislações em torno de educação escolar indígena e da saúde indígena no país, bem como as conquistas do movimento social indígena em torno dessas reivindicações. Identifica-se 0 interesse dos profissionais Kaingang pela ocupação de postos de trabalho principalmente no setor público, com incipiente intenção de emprego em empresas privadas na indústria, no comércio, no setor de serviços ou mesmo no setor primário (agricultura, pecuária, dentre outras), caracterizando-se a intencionalidade da formação de servidores públicos indígenas, mesmo que as decorrências desse 
interesse não se apresentem suficientemente debatidas (CAPELO; TOMMASINO, 2004).

Nesse contexto, o novo circuito de relações profissionais que possivelmente se caracteriza específico em cada uma das comunidades Kaingang (haja vista as históricas relações de poder nelas existentes) tem como referência inicial as instituições governamentais presentes e/ou atuantes nas terras indígenas, com destaque para a FUNAI, os Distritos Sanitários Indígenas, as Prefeituras Municipais e as Secretarias de Estado da Educação. Ressalta-se, ainda, a demanda por profissionais indígenas que venham a atuar na gestão de projetos vinculados às indenizações de empreendimentos hidrelétricos que impactaram territórios indígenas no Paraná e no país.

Constata-se, em especial na Rede Estadual de Educação do Paraná, a significativa criação de postos de trabalho para professores Kaingang nas escolas estaduais indígenas, principalmente com 0 processo de estadualização da educação escolar indígena a partir do ano de 2009, possibilitando a expansão da oferta do $2^{\circ}$. segmento do ensino fundamental e do ensino médio nas terras indígenas (AMARAL, 2010). Essa expansão, acompanhada da formação de pedagogos e professores Kaingang em diferentes licenciaturas nas universidades públicas, bem como da oferta de cursos de magistério Kaingang e de licenciaturas interculturais específicas, vem ampliando as vagas para professores Kaingang nos diferentes níveis e modalidades da educação básica, ainda que, até a presente data, infelizmente esse ingresso tenha ocorrido somente por meio de contratos temporários, tendo se realizado no ano de 2010 um debate inicial sobre a abertura de concursos públicos específicos no Paraná (AMARAL, 2010).

Esse processo pode provocar a reorganização da dinâmica curricular e linguística nas escolas estaduais nos territórios Kaingang, interrogando e repensando a lógica padronizada, disciplinar e homogeneizadora que ainda se apresenta hegemônica nesses espaços. Pode também instaurar uma renovação no circuito de trabalho existente nas referidas escolas, provocando uma transição do atual e majoritário quadro profissional não indígena para um majoritário quadro de profissionais indígenas habilitados nas escolas indígenas; esse fenômeno pode potencializar as relações de conflito e resistência por parte de todos os envolvidos, dada a existência de profissionais indígenas que possuem vínculo com o cacique e lideranças de determinados grupos faccionais e que não necessariamente sejam aprovados em concurso público específico. É possível haver também a posição por parte de caciques que queiram priorizar a permanência de profissionais não índios nas escolas dadas as negociações existentes com a sociedade local 
envolvente e, muitas vezes, pela descrença na capacidade dos profissionais indígenas recém-formados.

A ofensiva e a expectativa da ocupação dos postos de trabalho nessas instituições pelos novos profissionais Kaingang podem provocar novos conflitos, consensos e concorrências locais, vindo a determinar reorganizações nas esferas e relações de poder nas comunidades.

Desta forma, um segundo elemento estruturante na constituição desse novo circuito de trabalho Kaingang refere-se aos faccionalismos existentes nos territórios Kaingang, manifestos no processo de emissão da declaração de pertencimento étnico pelos caciques para que os candidatos indígenas se inscrevam no Vestibular dos Povos Indígenas do Paraná, bem como na definição de uma vaga para os profissionais indígenas para trabalharem nas instituições públicas que atuam nas terras indígenas.

Ao refletir sobre a construção da especificidade Kaingang em sua organização política e comunitária, principalmente na identificação de sua política interna e da existência de facções, vinculadas com o seu método de classificação, Fernandes (2003, p. 279-280) evidencia que:

As parentagens são as facções Kaingang. As parentagens são, de fato, grupos similares que se constituem mutuamente. São grupos que se constituem por oposição, sem dissolver a unidade Kaingang. 0 que as diferencia, é a relação que estabelecem com os troncos velhos, o foco ancestral que conecta a um território específico. Política e parentesco se fundem na organização social Kaingang através da categoria nativa tronco velho: ao mesmo tempo a referência ancestral genealogicamente traçada de um grupo doméstico e o critério de legitimidade política de uma parentagem. A rede de relações intercomunitárias é tecida com referência aos troncos velhos [...] facções são, então, grupos similares que se opõem sem dissolver a unidade fundamental [...] só são facções quando o cenário político exige [...] Quando entra em cena, a facção se cola às parentagens de forma indissociável.

Destaca-se a importância da compreensão dessa lógica tradicional de relações Kaingang pelo Estado na dimensão de suas políticas e programas governamentais, pelas organizações da sociedade civil que atuam junto a esta etnia, pelas Universidades, e mesmo para os jovens pertencentes a este grupo 
étnico. Constata-se a recorrente manifestação de profissionais Kaingang ao explicitar as relações políticas internas como um elemento definidor para o seu possível retorno à comunidade, considerando a existência de alianças e tensões entre diferentes grupos locais, disputando a atuação ou não dos profissionais indígenas recém-formados (AMARAL, 2010). 0 novo circuito de relações de trabalho e profissionais que passa a se constituir nas terras indígenas a partir dos egressos da universidade, pode provocar a reconfiguração das relações faccionais existentes em cada uma das terras indígenas, podendo também gerar novas posturas e compreensões acerca deste novo sujeito acadêmico e novo profissional Kaingang, dependendo das fricções e tensões que venham a se estabelecer.

Para além da abertura de postos de trabalho na aldeia ou no município de entorno, o possível retorno e acolhimento dos novos profissionais indígenas na aldeia dependerá das relações políticas internas e da posição ocupada pelos estudantes Kaingang e sua rede de parentesco no conjunto do faccionismo político existente na comunidade, determinando sua aceitação ou não pelos caciques e lideranças indígenas. Ainda que não existam estudos acerca desse fenômeno, observa-se que vários grupos familiares nas terras indígenas passam a preparar seus filhos para ingressar na Universidade como uma estratégia de melhorar as suas condições de vida ou mesmo pelo prestígio social e político possível, seja pela garantia da bolsa auxílio enquanto acadêmicos, seja pela possibilidade deles ocuparem postos de trabalho melhor remunerados nas aldeias ou fora delas. Isso também se justifica uma vez que parte dos investimentos e esforços empreendidos pelos profissionais indígenas na sua formação acadêmica tem como referência 0 seu próprio mérito e 0 apoio de sua família, tendo em vista as ausências institucionais, principalmente das Universidades, para esse percurso (AMARAL, 2010).

Importante destacar que a presença desse novo profissional Kaingang na comunidade, pode provocar o redesenho nas relações de status e de prestígio social local, seja pela influência política e técnica que esses novos sujeitos passam a ter, seja pela capacidade de renda e de consumo a eles possível, uma vez que passam a ter as melhores remunerações na aldeia e entre seu grupo familiar

\footnotetext{
${ }^{8}$ Considerando as diferenciadas dinâmicas de mobilidade nas relações de poder próprias de cada terra indígena, faz-se fundamental o desenvolvimento continuado de pesquisas e estudos que venham pautar o ingresso e acolhimento dos novos profissionais indígenas no interior das comunidades, bem como as rejeições e resistências que possam ser explicitadas pelos caciques e lideranças indígenas para com esses profissionais.
} 
(AMARAL, 2010). Esse novo padrão de consumo9 pode provocar maiores assimetrias e multiplicar as desigualdades nas relações sociais, políticas e econômicas locais, alterando as experiências de reciprocidade existentes (FERNANDES, 2003).

0 terceiro elemento estruturante na constituição de um novo circuito de trabalho Kaingang refere-se à renovação do perfil profissional existente nos territórios Kaingang, até então composto por lideranças indígenas que passaram a vincular-se à FUNAI como servidores públicos de carreira, sem necessariamente possuir uma graduação profissional ou concurso público.

Pode-se compreender que a presença desses profissionais indígenas (muitos deles atualmente em processo de aposentaria) tenha sido uma estratégia do Estado brasileiro (desde a criação do SPI e posteriormente da FUNAI) em arregimentar, contratar e treinar indígenas para ocupar postos de trabalho dentro destas instituições e atuantes nas terras indígenas, numa atitude de sequestro cultural e subjetivo desses sujeitos a serviço da política de integração nacional e como uma de suas formas de controle e de legitimação de suas políticas. Entendese também que esse tipo de envolvimento, ainda que complexo, pode ser também compreendido dialeticamente como uma forma estratégica de ocupação e resistência dos espaços institucionais pelos indígenas, em especial pelos Kaingang, não havendo, contudo, uma profunda reflexão sobre suas implicações.

Os novos profissionais Kaingang trazem na sua bagagem formativa os conhecimentos acadêmicos sistematizados buscados e aprendidos na universidade e colocados, possivelmente, a serviço das comunidades, podendo vir a recaracterizar o perfil de servidor público indígena que venha nelas atuar. A presença e atuação desses novos sujeitos, ocupando fundamentalmente cargos em diferentes instituições governamentais, podem provocar transformações em médio e longo prazo nessas instituições, vindo a alterar a cultura organizacional e a característica pública de seu atendimento. Essa perspectiva pode se efetivar dependendo do nível de envolvimento e adesão dos recém-formados a essas instituições, do seu pertencimento étnico-comunitário, de sua formação acadêmica, técnica e política, das funções institucionais a serem exercidas,

\footnotetext{
${ }^{9}$ Importante destacar a ausência de pesquisas voltadas a esse fenômeno, sendo o mesmo recente no que se refere à emergência e trajetória desses novos profissionais indígenas e das relações de trabalho por eles desenvolvidas nas terras indígenas. Ressalta-se, por meio de pesquisas que vimos desenvolvendo, uma mudança no padrão de consumo (automóveis, reforma de suas residências, vestuários etc.) por esses profissionais, nas terras indígenas, ficando em evidência essas novas diferenças sociais, dependendo da localidade e do grupo familiar envolvido.
} 
aderindo ou resistindo às sutis estratégias de sequestro subjetivo pela dinâmica institucional, por elas historicamente constituídas (FARIA, 2007).

Nessa lógica, o esse novo circuito de trabalho pode instaurar um momento diferente na história do desenvolvimento social, cultural, político, territorial e econômico dos povos indígenas do Brasil, dependendo da direção, intencionalidade e qualidade deste processo formativo, das conquistas políticas e sociais dos povos indígenas frente ao Estado, bem como, do nível das mudanças na cultura organizacional das agências oficiais ora existentes, a serem protagonizadas pelos novos profissionais. Emerge, desta forma, no Brasil, o debate sobre a nova relação entre os povos indígenas e 0 Estado brasileiro (pósConstituição Federal de 1988) e sobre qual política indigenista se quer desenvolver, tendo em vista a garantia da participação efetiva dos povos indígenas (LIMA, 2002).

\section{CONSIDERAÇões FinAIS}

Os aspectos apresentados nesse trabalho refletem a possibilidade dos acadêmicos e profissionais indígenas, em especial os Kaingang, tornarem-se cada vez mais sujeitos do seu processo formativo, tendo em vista as possibilidades que para eles se abrem na ocupação dos atuais e de novos postos de trabalho em suas comunidades de origem, em outras terras indígenas, na esfera municipal, estadual e federal, fundamentalmente na gestão das políticas públicas, na medida em que essas avançam ou retroagem.

Trata-se não somente da constituição de um novo circuito de trabalho Kaingang, mas fundamentalmente, da possibilidade de construir, reconhecer e dar visibilidade à novas lógicas de gestão das políticas sociais públicas, produzidas por sujeitos pertencentes a diferentes grupos étnicos e que, mediados por seu duplo pertencimento, transitam por diferentes cosmologias e especificidades na organização social e política de suas comunidades. Importa revelar a emergência de um novo tipo de profissional que se reconhece indígena e que pode vir a assumir e/ou afirmar sua condição enquanto intelectual orgânico de sua comunidade e de seu grupo étnico (PAULINO, 2008), compreendendo-se e reconhecendo-se em espaços contraditórios que não foram formatados para atender os interesses dos povos indígenas, mas que podem ser por eles ocupados e recriados. 


\section{REFERÊNCIAS}

AMARAL, Wagner R. As trajetórias dos estudantes indígenas nas Universidades Estaduais do Paraná: sujeitos e pertencimentos. Tese (Doutorado em Educação) - Universidade Federal do Paraná. Curitiba, 2010.

BARTH, Frederik. Grupos étnicos e suas fronteiras. Bergen, 0slo: Universitetsforlagets, 1969. In: POUTIGNAT, Philippe.; STREIFF-FENART, Jocelyne. Teorias da etnicidade: seguido de grupos étnicos e suas fronteiras de Fredrik Barth. São Paulo: Ed. UNESP, 1998. p. 185-228.

CAPELO, Maria Regina C.; TOMMASINO, Kimiye. Conflitos e dilemas da juventude indígena no Paraná: escolarização e trabalho como acesso à modernidade. Cadernos CERU, São Paulo, n. 15, 2004.

FARIA, José Henrique de. Economia política do poder. Curitiba: Juruá, 2007. v. 1.

FERNANDES, Ricardo C. Política e parentesco entre os Kaingang: uma análise etnológica. 2003. Tese (Doutorado em Antropologia Social) - Universidade de São Paulo, São Paulo, 2003.

IBGE. Censo 2010: população indígena é de 896,9 mil, tem 305 etnias e fala 274 idiomas. Disponível em: <http://censo2010.ibge.gov.br/noticiascenso?busca $=1 \& \mathrm{id}=3 \&$ idnoticia $=2194 \& \mathrm{t}=$ censo-2010-poblacao-indigena-896-9-miltem-305-etnias-fala-274\&view $=$ noticia $>$. Acesso em: 27 out. 2014.

LIMA, Antonio C. de Souza. Estado e povos indígenas no Brasil: bases para uma nova política indigenista, Rio de Janeiro: Contra Capa Livraria/LACED, 2002.

LUCIANO, Gersem dos Santos. $O$ índio brasileiro: o que você precisa saber sobre os povos indígenas no Brasil de hoje. Brasília: Ministério da Educação, Secretaria de Educação Continuada, Alfabetização e Diversidade. LACED/ Museu Nacional, 2006.

MOTA, Lucio Tadeu. Os índios Kaingang e seus territórios nos campos do Brasil meridional na metade do século XIX. In: MOTTA, Lucio Tadeu; NOELLI, Francisco S.; TOMMASINO, Kimiye. (Org.). Uri e Wãxi: estudos interdisciplinares dos Kaingang. Londrina: UEL, 2000.

OLIVEIRA, João Pacheco; FREIRE, Carlos A. R. A presença indígena na formação do Brasil. Brasília: MEC/SECAD; LACED/ Museu Nacional, 2006.

PAUlinO, Marcos M. Povos indígenas e ações afirmativas: o caso do Paraná. 2008. Dissertação (Mestrado em Educação) - Universidade Federal do Rio de Janeiro, Rio de Janeiro, 2008. 
PERES, Sidnei C. Ação afirmativa e direitos culturais diferenciados: as demandas indígenas pelo ensino superior. In: LIMA, A. C. S.; BARROSO-HOFFMANN, Maria (Org.). Desafios para uma educação superior para os povos indígenas no Brasil: políticas públicas de ação afirmativa e direitos culturais diferenciados. Rio de Janeiro: Museu Nacional/LACED, 2007.

TOMMASINO, Kimiye. Território e territorialidade Kaingang: resistência cultural e historicidade de um grupo Jê. In: MOTTA, Lucio Tadeu; NOELLI, Francisco S.; TOMMASINO, Kimiye. (Org.). Uri e Wãxi: estudos interdisciplinares dos Kaingang. Londrina: UEL, 2000.

TOMMASINO, Kimiye. A história dos Kaingang da bacia do Tibagi: uma sociedade Jê meridional em movimento. 1995. Tese (Doutorado em Antropologia Social) - Universidade de São Paulo, São Paulo, 1995.

TOMMASINO, Kimiye; FERNANDES, Ricardo C. Kaingang. In: INSTITUTO SOCIOAMBIENTAL - ISA. Povos indígenas no Brasil. 2001. Disponível em:<http://pib.socioambiental.org/pt/povo/ kaingang $>$. Acesso em: 28 nov. 2013.

VEIGA, Juracilda. Organização social e cosmovisão Kaingang: uma introdução ao parentesco, casamento e nominação em uma sociedade Jê meridional. 1994. Dissertação (Mestrado em Antropologia) - Universidade de Campinas, Campinas, 1994.

VEIGA, Juracilda. Cosmologia e práticas rituais Kaingang. Tese (Doutorado em Antropologia) - Universidade de Campinas, Campinas, 2000.

VEIGA, Juracilda; D’ANGELIS, Wilmar da R. Bilingüismo entre os Kaingang: situação atual e perspectivas. In: MOTTA, Lucio Tadeu; NOELLI, Francisco S.; TOMMASINO, Kimyie (Org.). Uri e Wãxi: estudos interdisciplinares dos Kaingang. Londrina: UEL, 2000.

WOLF, Eric R. Aspectos das relações de grupo em uma sociedade complexa: México. (1956). In: FELDMAN-BIANCO, Bela; RIBEIR0, Gustavo L. (Orgs.). Antropologia e poder. Contribuições de Eric R. Wolf. Brasília: Editora UnB; São Paulo: Imprensa Oficial de São Paulo; Editora Unicamp, 2003. 